\title{
Simultaneous activities in the household and residential electricity demand in Spain
}

Article

Accepted Version

Torriti, J. and Santiago, I. (2019) Simultaneous activities in the household and residential electricity demand in Spain. Time \& Society, 28 (1). pp. 175-199. ISSN 1461-7463 doi: https://doi.org/10.1177/0961463X16656867 Available at https://centaur.reading.ac.uk/65717/

It is advisable to refer to the publisher's version if you intend to cite from the work. See Guidance on citing.

To link to this article DOI: http://dx.doi.org/10.1177/0961463X16656867

Publisher: Sage

All outputs in CentAUR are protected by Intellectual Property Rights law, including copyright law. Copyright and IPR is retained by the creators or other copyright holders. Terms and conditions for use of this material are defined in the End User Agreement.

\section{www.reading.ac.uk/centaur}

\section{CentAUR}

Central Archive at the University of Reading

Reading's research outputs online 


\title{
Simultaneous activities in the household and residential electricity demand in Spain
}

\begin{abstract}
Recent research and policy studies on the low-carbon future highlight the importance of flexible electricity demand. This might be problematic particularly for residential electricity demand, which is related to simultaneous consumers' practices in the household. This paper analyses issues of simultaneity in residential electricity demand in Spain. It makes use of the 2011 Spanish Time Use Survey data with comparisons from the previous Spanish Time Use Survey and the Harmonised European Time Use Surveys. Findings show that media activities are associated the highest levels of continuity and simultaneity, particularly in the early and late parts of the evening during weekdays.
\end{abstract}

\section{Keywords}

Electricity demand; Simultaneity; Social practice theory; Spain; Time use 


\section{Introduction}

Recent research and policy studies on the low-carbon future highlight the importance of a more flexible demand of electricity. The integration of new technologies, like heat pumps and electric vehicles, is expected to bring about increases in peak electricity demand which may not be met by intermittent supply (IEA, 2011). Simultaneity in time and space of consumer practices is a major cause for residential peak electricity demand.

Following Becker's (1965) rational economic modelling of household time use, the issue of how consumption relates to time has been approached from various angles. Rational action theories of consumption and time offer causal explanations of changes in the relationship between consumption and time. They are based on the assumption that work and consumption are practices that consume time. Since volumes of time are determined, extra time spent on either practice will reduce the time available for other practices (Southerton, 2003). Attempts to move away from the causal relations rationale explored the extent to which increases in working hours have brought about a reduction in domestic activities (Hochschild, 1997). Practice theories consider the relation between time and consumption in relation to the fact that human activities are ordered recursively across space and time (Giddens, 1984). The patterning of social life is a consequence of routine, collective and conventional nature of consumption (Reckwitz, 2002). From practice theory, simultaneity can be defined as the result of the socio-temporal organisation of daily practices.

Understanding issues of simultaneity in residential electricity demand for a large number of households, i.e. a whole country, is the empirical endeavour of this study. The paper aims to understand when consumer practices take place simultaneously in a large number of households and how flexible they are in terms of timing and duration. It identifies some of the key patterns of simultaneous consumption underpinning electricity demand. Simultaneity is investigated in four domains. First, sequential and simultaneous engagement in diverse practices becomes of particular interest especially when involving people belonging to disparate and heterogeneous social networks. Understanding peaks in energy demand is a matter of understanding how simultaneous and synchronised practices are across society (Mattioli et al, 2014; Walker, 2014). Hence, we will look at times of the day when respondents were carrying out the same activities. Second, we will turn to activities in the household. TV use is generally seen as the product of routines in individual households' schedules (Robins, 1995). From practice theory the household is one of the key places for understanding the intensification of simultaneous and multiple consumption (Silverstone, 1993). The household can be seen as the venue for inescapably normal processes because it is where people typically engage in several practices at the same time, all using very 
similar equipment. The choice to focus on TV is driven by the methodological aspiration to directly link practices with actual electricity consumption.

Third, computer use should illustrate practices of consumption taking place not simply for their own sake, but as part of a wide range of varied rewards. Computer use is an example of the dilation of workrelated tasks in time-space dimensions which are distant from the work place. It is also an example of how forms of leisure are distant in space from venues designed for leisure. Fourth, the literature on the division between time at home and work is very large, but lacks significant evidence (Gershuny, 2000). The synchronisation of activities within the household is dependent on the 'time budget', where fixed activities like paid work require a high degree of commitment and represent fundamental anchor points in an individual's daily schedule (Kwan, 2002). Consequently, this paper follows the suggestion of using point-based approaches to appraise the physical separation between key reference locations i.e. home and work (Neutens et al, 2011). In theories of practice it is acknowledged that the distinction between work and leisure is becoming increasingly blurred, partly due to the role of working from home (Cogoy, 1999), The workplace can be seen as a carrying intrinsic social and personal meanings which are fundamentally distinct from the household (Reisch, 2001). Simultaneity and continuous hours in the work place yield implications of time use rebound effects -in terms of time not spent in the householdand implicit energy consumption in the workplace.

Time use data are used along with appliance specific data in an attempt to represent some of the electricity loads through a break-down of activities in the household. Consumers' activities are analysed from the 2010 Spanish Time Use Survey and brief comparisons are drawn with the previous 1996 Spanish Time Use Survey and the European Harmonised Time Use Surveys.

After this introduction, the paper defines concepts of simultaneity and flexibility in electricity demand; reviews how time-use data have been utilised to assess trends in residential electricity demand profiles; presents findings from the 2010 Spanish Time Use Survey; and discusses some of the methodological, theoretical and policy issues associated with simultaneity, time-use data and electricity demand.

\section{Simultaneity and peak demand}

Currently consumers pay for the amount of electricity they use regardless of when they consume it. For generators providing electricity at peak times is more expensive than at off-peaks and even though wholesale prices tend to be higher during these periods, there is widespread concern that not enough capacity will be built to ensure adequate capacity, potentially leading to black-outs over coming years. As a result, simultaneity of electricity consumption is associated with high societal costs. In addition, the 
integration of renewable sources of electricity, together with electric vehicle charging, greater use of combined heat and power and heat pumps, will trigger the requirement for demand profiles which throughout the day match such high level of variation in supply (Foxon, 2013). Issues with peak demand lead suppliers to think about ways to change consumption patterns (i.e. demand profiles) throughout the day. Demand Side Response or simply Demand Response is widely seen as the main intervention tool to address issues of peaks in electricity demand (Barton et al, 2013; Torriti et al, 2010). Variations can be in terms of volumes or price and are communicated to the demand side. Shifting demand in time involves a collection of actions which ranges from meeting short term needs at times of unexpected crunch in supply to longer term improvement in the efficiency with which energy services meet supply in recurrent peak episodes (Grünewald and Torriti, 2013). Demand Side Response is experiencing significant growth throughout several European countries, including the UK, France, Germany, Sweden, Finland, etc. Energy aggregators, which are the commercial enablers of Demand Side Response activities, are mainly focussing on retail and industrial consumers rather than residential ones (Torriti and Grünewald, 2014). However, the introduction of smart meter roll-outs with half-hourly metering data communicated from households to utilities, along with time of day pricing programmes will increase the opportunities for future penetration of residential Demand Side Response. Aggregators may reach out to portfolios of residential consumers and amass their otherwise negligible loads to fulfil Demand Side Response contracts with system operators. Through the smart meter, consumers will receive either price or peak signals and will be able to have reduced prices when they respond to such signals. Besides these forms of dynamic pricing, residential Demand Side Response might take the form of automated controllers which respond to peak signals following pre-set schedules for turning appliances down or even direct load control from aggregators. For this reason, the focus on simultaneity of activities in the household is a first step towards understanding the flexibility potential of residential demand profiles. How can in principle Demand Side Response make existing residential demand profiles more flexible? For instance, since electricity demand patterns are predominantly diurnal, less prominent peaks in demand might occur if consumers were subjected to time-of-use tariffs or even more sophisticated forms of real time pricing.

\section{Flexible electricity demand in household and energy economics}

Traditionally, the load profiles associated with residential electricity demand have been considered as inflexible. This means that the time of the day when consumers use electricity is relatively repetitive and predictable. The inflexibility of demand often relates to time-bound societal needs for simultaneous consumption. Two disciplinary angles, i.e. household economics and energy economics, considered extensively the causes and effects of the inflexibility and simultaneity in residential electricity demand. 
In the household economics literature focuses the discussion on simultaneity and timing of consumption with particular emphasis on behavioural determinants (such as the timing of use per appliance), which are generally classified as flexible decisions requiring little or no financial investment. These counterpoise physical determinants of appliances (e.g. the energy efficiency of an appliance) which result in relatively 'fixed' decisions (Mansouri et al, 1996). However, the extent to which the supposedly flexible component of consumption can be translated into elasticity of energy demand is very limited due to the low willingness of consumers to substitute an appliance use for another. Elasticity of substitution tends to be constant across demographic-appliance stock variables (Kasulis et al, 1981).

In the energy economics literature, inflexibility has conventionally been associated with inelasticity. Changes in price over short and medium periods would yield only minor changes in electricity demand (Bernard et al, 2011; Borenstein, 2005; Filippini, 1995; Kamerschen, and Porter, 2004; Silk and Joutz, 1997). Two underpin justify the inelasticity of residential electricity demand. First, the flat tariffs which most residential consumers have been exposed to over the last decades prevent the existence of signals regarding the true costs of electricity. An increase in price of $100 \%$ typically is expected to trigger reduction of around $20 \%$ change in demand (EPRI, 2008). Responses to peak period prices lead to price elasticities of 0.02 to 0.1 (Faruqui and Sergici, 2009). Because of wide-spread flat tariffs customers do not operate in a responsive manner in the retail market. The image of a supermarket without price labels on the products can figuratively explain the lack of price signals in electricity markets. One of the unintended consequences of the lack of information on prices is that consumers might simultaneously opt for sub-optimal choices (Dana, 1999). In the energy sector simultaneous demand at the time of low supply is extremely problematic as it forces energy companies to produce expensive and frequently highly carbon intensive extra generation. Second, at least in the developed world, electricity prices are usually too low to make any impact on a large scale. Electricity prices are typically low enough that electricity payments make up only a small portion of the average household's budget, and consumers likely perceive electricity as a necessity during peak times (Thorsnes et al, 2012).

\section{Simultaneity, electricity demand and consumer practices}

In order to understand whether flexibility is possible in the realm of residential electricity demand, the issue of why electricity is used at certain times of the day needs to be addressed. Consumers do not consume electricity for the sake of it, but in order to carry out those activities and practices which are required by their social sphere and, in some cases, might be dictated by their preferences. The starting point is to examine when simultaneity occurs and which practices trigger it. 
Our analysis of time use data relies theories of practice because these give some significant insights as to the distinction between those activities in the household which are strictly necessary, hence rarely cancellable or postponable, and those activities which are linked with intentional preference, hence in principle more flexible. Cooling, space and water heating denote significant shares of residential energy consumption in most Southern European countries (Gago et al, 2011). Because they are related to issues of comfort (Shove, 2004), they trigger interesting questions with regards to simultaneity and flexibility. However, this paper cannot focus on cooling, space and water heating for two reasons. First, the activities in the time use data do not address these energy demand needs. Second, since cooling, space and water heating involve several fuels - such as gas and electricity - the variation from household to household is extremely high and dependant on technical performance of boilers, size of the household, external temperatures. These variables cannot be measured from time use data only. As a result, our analysis comprises only activities and practices which can be reconnected to a single energy fuel (i.e. electricity) and which by definition are detached from rigid social needs and conventions. Efforts to quantify the total number of hours spent carrying out specific activities in the household can explain the meanings of the activities so described and about their timing, i.e. their duration and sequential ordering (Shove, 2003).

\section{Measuring simultaneity: time use surveys}

\section{Previous research work on time use data and electricity demand profiles}

A recent inter-disciplinary research approach consists of employing time use data (i.e. tracking residential users in and out of the household) and linking them to residential energy demand. Time use data have been used before in energy demand modelling work at the national level in the UK (Richardson et al, 2008; Richardson et al, 2010), France (Wilke et al, 2013), Spain (López-Rodríguez, 2013) and Sweden (Widén and Wäckelgård, 2010; Widén et al, 2009a and 2009b). The general approach of these studies tends to rely on either measured time use survey data or synthetic stochastic models. Two seminal studies lay the foundations for residential electricity demand models based on time use data. Firstly, Wood and Newborough (2003) use three characteristic groups to explain electricity consumption patterns in the household: "predictable", "moderately predictable" and "unpredictable". Predictable loads consist of limited cyclic loads taking place at a time of passive occupancy, that is when a dwelling is unoccupied or all the occupants are asleep. Moderately predictable loads relate to the habitual behaviour of occupants. Unpredictable loads are significantly arbitrary and are generally excluded from time-use studies. Secondly, Firth et al (2008) analyse groups of electrical appliances (continuous and standby, cold and active appliances) in terms of time of the day when they are likely to be running. The authors distinguish between deterministic and stochastic timing of appliance use. A review of time use studies in the area of residential electricity demand is presented in Torriti (2014). 


\section{The Spanish Time Use Survey}

Time Use Surveys originate from the beginning of the Twentieth Century. Initially they were carried out mainly in urban areas in Europe and the United States. Over the last fifty years, Time Use Surveys have extended to nationally significant, Government-led projects. The main statistical measuring tool consists of a time diary where the sequence and duration of activities are noted. Juster et al (2003) provide a review of empirical studies relying on time use data. Researchers employing time use data measured total national production, compared the distribution of different activities and looked at issues of sequencing as chains of events (Vikat and Boko, 2013). Time use data reveal sequencing and time-space dimensions for activities which people carry out most days, such as eating, personal care or sleeping. Compared with studies modelling intra-personal change and intra-personal differences in daily behaviours, this work is centred in simultaneous activities which may relate to peak energy consumption. Studies looking at intra-personal variation require longer observation of the same people, whereas simultaneity of large population samples is better captured through time use techniques (Schulz and Grunow, 2012).

In Spain, national Time Use Survey started in the 90s. It followed the criteria of the Eurostat project on time use data harmonisation. In 1996 the first 'Time Use in Spain Pilot Study' was published by the Instituto Nacional de Estadistica. The most recent Time Use Survey follows the guidelines for the Harmonised European Time Use data with a sample population of approximately 5,000 consumers.

The 2010 Time Use Survey comprises data collected in the years 2009 and 2010. The dataset is publically available online. The break-down of activities includes: personal care, paid work, studies, household and family, volunteer work and meetings, social life and recreation, outdoor sports and activities, hobbies and computers, media, journeys, and unspecified time use. The activities are classified in terms of age, gender and day of the week (Monday to Friday, Saturday and Sunday).

Table 1 shows the average time spent in main activities by types of days. The activities were grouped to follow a similar taxonomy to those in the Spanish Time Use Survey, with the exception of Outdoor activities and Social Life which were grouped in the same category. The main focus of the analysis is on household activities, with emphasis on TV average loads; average loads of desktop and laptop computers; and percentage of households with at least one occupant not sleeping. Initially outdoor activities (e.g. travel, outdoor activities) are 
also taken into account to scope for the number of persons conducting the same main activity at the same time of day and each hour for all days of the week and weekdays only. The rationale for following this approach is that there are higher chances of peak demand when simultaneous activities are taking place both outside (e.g. continuous work and travel) and inside the household (e.g. personal care and media).

Table 1-Average hours per day spent conducting main activities

\begin{tabular}{lrrrr}
\hline & $\begin{array}{l}\text { Monday } \\
\text { to } \\
\text { Thursday }\end{array}$ & Friday & Saturday & Sunday \\
\hline $\begin{array}{l}\text { Personal care } \\
\text { Working }\end{array}$ & 10 & 10 & 11 & 12 \\
$\begin{array}{l}\text { Studying } \\
\text { Household }\end{array}$ & 5 & 4 & 1 & 1 \\
$\begin{array}{l}\text { and family } \\
\text { care }\end{array}$ & 0 & 0 & 0 & 0 \\
$\begin{array}{l}\text { Outdoor } \\
\text { activities and }\end{array}$ & 3 & 3 & 3 & 3 \\
$\begin{array}{l}\text { social life } \\
\text { Hobbies and }\end{array}$ & 0 & 0 & 1 & 1 \\
computers & & & & \\
$\begin{array}{l}\text { Media } \\
\text { Travel }\end{array}$ & 2 & 2 & 3 & 2 \\
\hline
\end{tabular}

\section{Findings}

\section{Carrying out the same activities simultaneously}

From an electricity consumption perspective, the most significant data that Time Use Surveys can offer are in relation to simultaneous activities. The more consumers are carrying out the same activities and practices at the same time, the higher the chances of increases in peak demand. This is because the nature of electricity demand is stochastic, with high variations from a single user to the other in the same period. However, the classification in Time Use Surveys can help breaking down the proportions of consumers who are carrying out the same main activity at the same time of day per each hour and give insights as to level of simultaneity of practices. Figure 1 shows the percentage of Spanish consumers involved in the same activity at the same time of day at the beginning of each hour. 
Figure 1- Percentage of persons conducting the same main activity simultaneously (all days of the week)

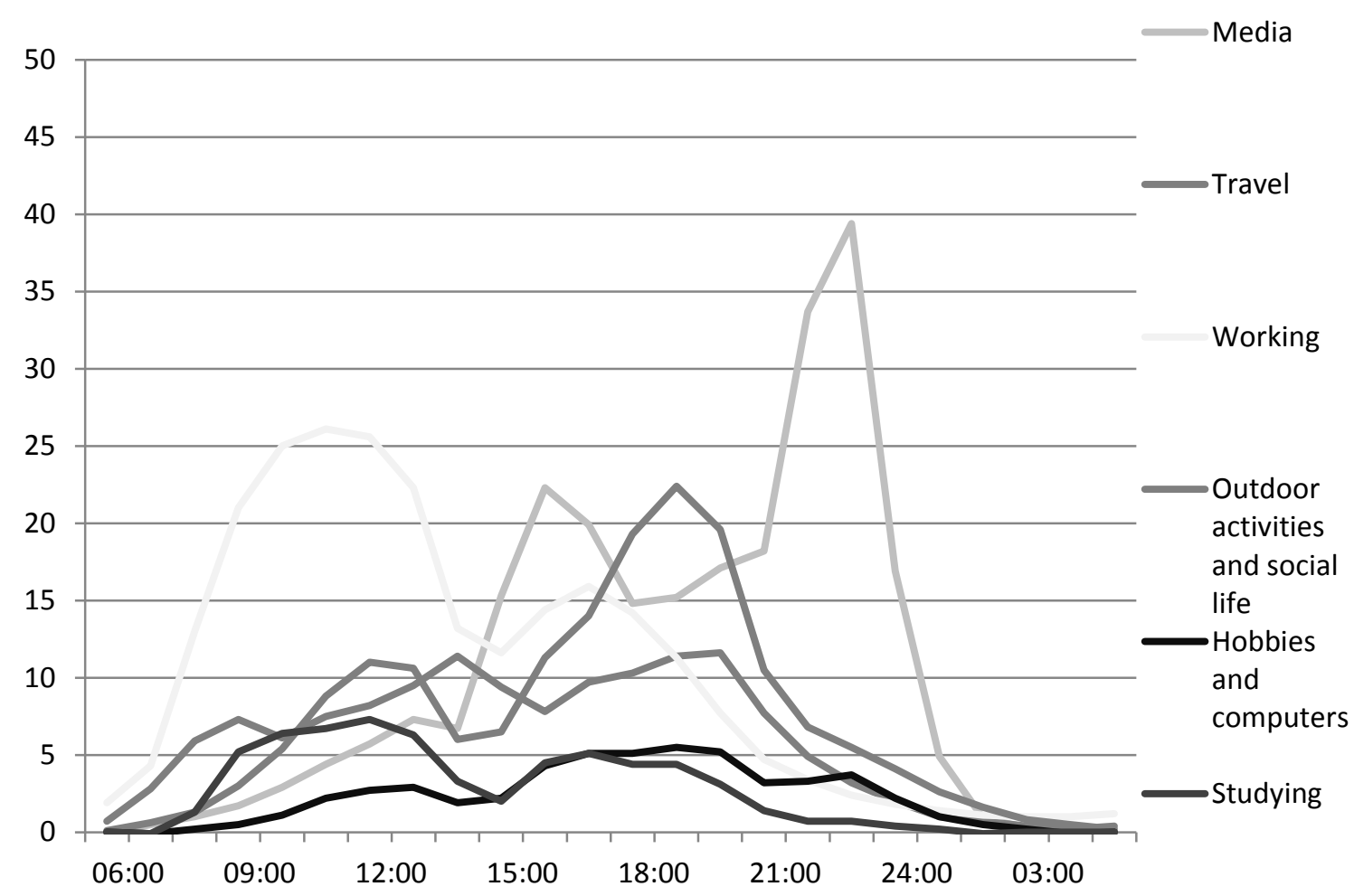

Media-related activities present the highest peak in Figure 1. The continuity of activities carried on from the previous hour has significant impacts with regards to simultaneity of electricity consumption. There is substantial continuity in those individuals who are involved in media activities between 19:00 and 23:00. This means that the load profile associated with the individual media device will be flat for an average period of four hours. The second peak taking place in Figure 1 refers to people who continue to work (as they did in the previous hour) in the morning. This second peak is even more obvious when looking at time use survey data for weekdays only (Figure 2). The distinction between weekdays and weekend is considered relevant both in terms of consumer practices and energy demand modelling. Consumer practice theory emphasises how certain activities are conducted either during weekdays (e.g. travelling to work by car as habit driven by personal need and colleagues) or at the weekend (e.g. going for a drive at the weekend draws upon conventions of independent holiday travel (O’Connell, 1998)). In their review of empirical studies on energy demand modelling, McLoughlin et al (2011) find that the distinction between weekday and weekend days is one of the most significant in the literature. Different behavioural patterns between 
the weekend and weekdays explain the necessary distinction between the two when modelling energy demand in buildings (Yao and Steemers, 2005).

\section{Figure 2- Percentage of persons conducting the same main activity simultaneously (week days only)}

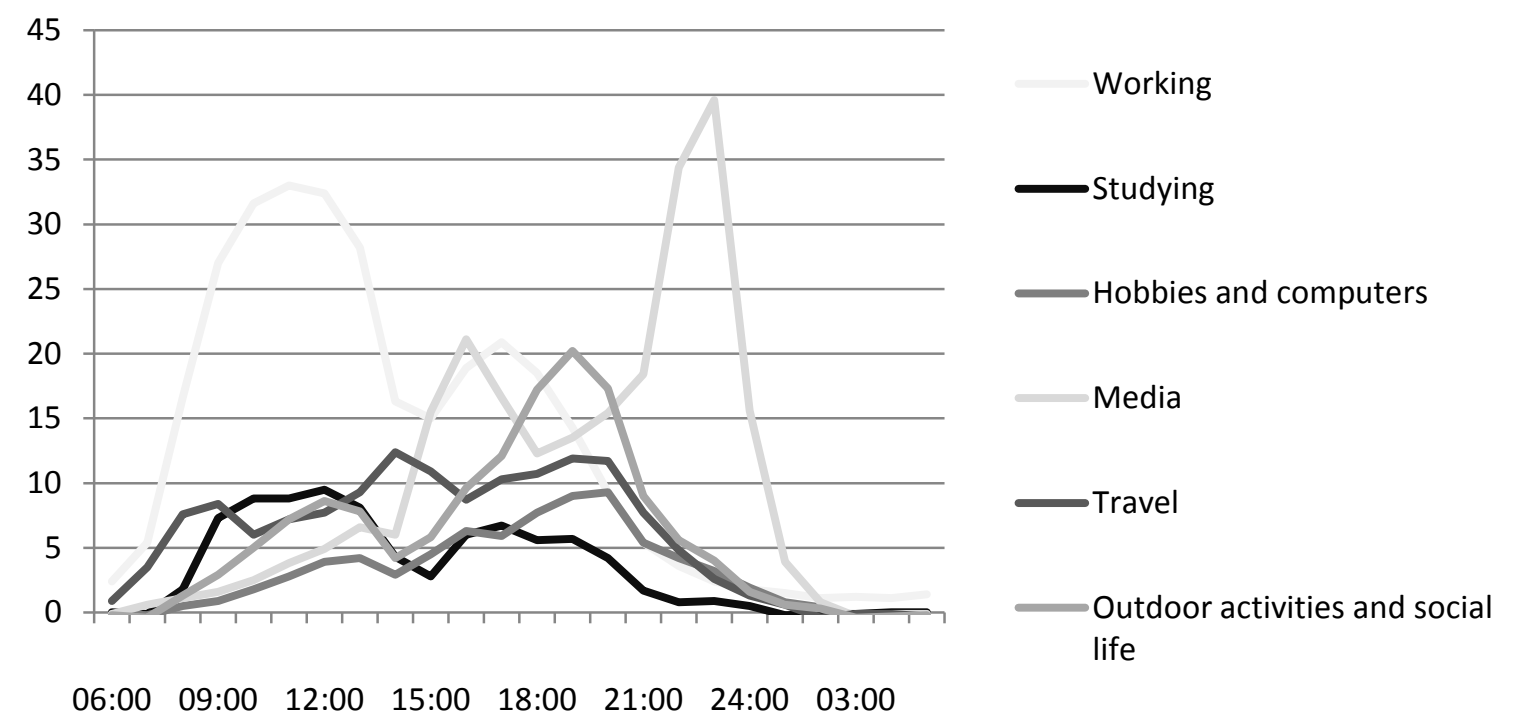

Simultaneous activities in the household: TV

The Time Use Survey data indicate the amount of time spent on media both on aggregate and disaggregate (i.e. reading, watching television, DVDs and videos, and listening to the radio or recordings).

An indication of how the time associated with TV watching activities affects electricity consumption is given by the average electricity consumption of Spanish TV devices taken from the Spanish Survey on Equipment and Use of Information Technologies and Communication in Households (National Statistical Institute, 2010) and the Homes and Environmental Survey (National Statistical Institute, 2008). Using time use data, average Spanish efficiency for TV devices, and average TV population, it is possible to model linearly the time use demand curve for TV activities as follows. Time use demand for TV activities at the time $j$ is

$D_{j}=\left[\left(U_{j} \times P\right)\right] \times K$, 
where $U_{j}$ is the total number of households with consumers involved in watching TV at time $j ; K$ is a parameter representing average Spanish efficiency consumption for TV devices; and $P_{i}$ is the average TV population in Spain. Two conditions which will need to be applied are:

$\mathrm{U}_{\mathrm{j}} \mid \mathrm{j} \in(0,24), \frac{U_{j}}{N} \geq 0$,

which means that the cumulative marginal value of time use TV should always remain positive, given the overall population $(N)$ of TV users. This is because we are assuming that significant load can only be extracted from conditions where consumers do not disconnect from TV immediately after switching them on. For this reason Figure 3 does not include any activity taking place between 1:00 and 5:00.

The average loads associated with TV are shown in Figure 3. Loads for weekday and weekend are presented in a range which represents the uncertainty related to number of devices per household. This varies from 1 to 2.2 appliances per household. The weekday (127 $\mathrm{MWh}$ ) and weekend (274 MWh) peaks are both taking place between 22:00 and 23:00 and have very similar size. The most significant variation between weekday and weekend occurs between 14:00 and 18:00.

\section{Figure 3-TV average loads}

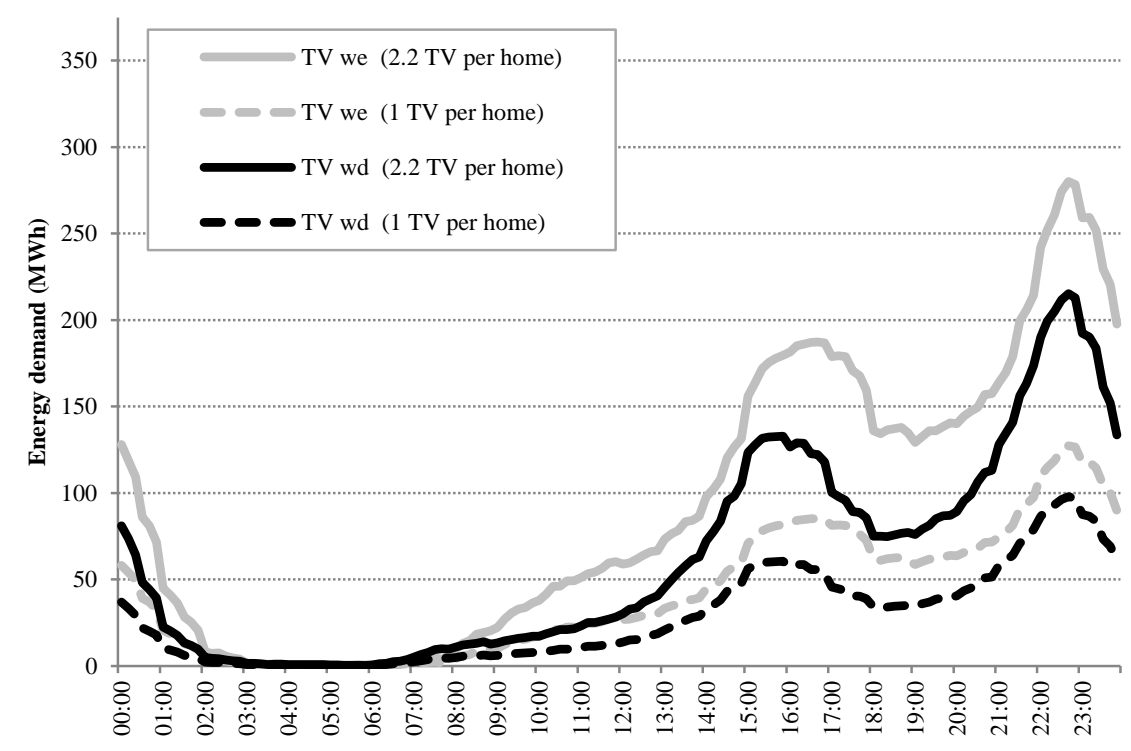


In the Spanish Time Use the activity computer use is separate from arts and hobbies and games. The time use data do not allow us to make the distinction between leisure-related computer use work-related computer use. This is an example of how computers reduce the time-space distance between the work place and the household. In order to model the energy consumption associated with computer use in the household, we repeat the same procedure as with TVTV, i.e. relying on data on the percentages of houses equipped with these devices from the Spanish Survey on Equipment and Use of Information Technologies and Communication in Households (National Statistical Institute, 2010) and the Homes and Environmental Survey (National Statistical Institute, 2008). The power consumption associated with each device was based on an individual standard model calculation from the Equipment Harmonic Database, which contains information about measurements made in different laboratories of different types of house-hold appliances and office equipment.

\section{Figure 4-Average loads of desktop and laptop computers}
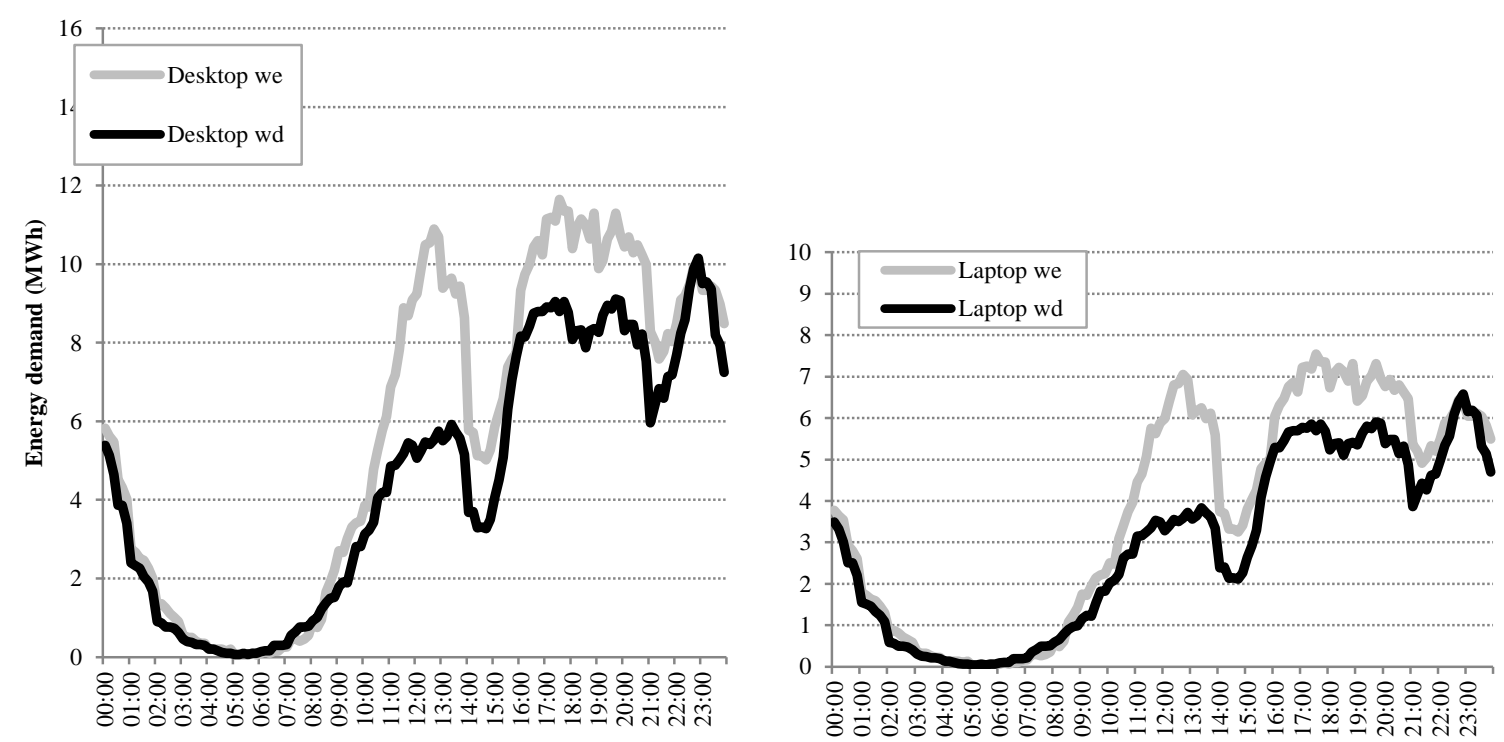

Figure 4 shows the average national electricity loads associated with desktop and laptop computers, breaking findings down for weekdays and weekend days. As for TV, we are assuming that significant loads are only extracted from periods when consumers do not turn laptops and desktops off immediately after switching them on. The highest peaks take place 
between 11:30 and 13:30 and between 16:30 and 20:30 on weekend days. The weekday peak in the computer-related electricity load takes place between 22:00 and 23:00. A second peak during weekdays occurs between 16:30 and 19:30. Overall, the consumption from computer use in Figure 4 is much lower than consumption for TV (Figure 3). This has to do with both the appliance efficiency, which is higher for most types of laptops than e.g. flat screen televisions (although most desktops have lower efficiency ratings than several types of TVs being watched in Spain) and lower penetration of computers than TVs in Spain (LópezRodríguez et al, 2013).

\section{Same activities at work}

The percentage of persons who are working at the same time of the day at the beginning of each hour gives an indication of the type of simultaneity inherent to work-related activities. Figure 5 illustrates the percentage of people involved in continuous hours at work. This means that between a one-hour period and the next hour the worker has not had any breaks from work. The highest level of continuity is associated with night time jobs. During weekdays a great number of night workers starts the shift (and, correspondingly, electricity consumption) at 2:00 and will not stop until about 8:00. As expected, the amount of people involved in continuous work hours is much lower for weekend days then weekdays. However, the trend is very similar both for weekdays and weekend. 


\section{Figure 5- Percentage of persons working on continuous working day}

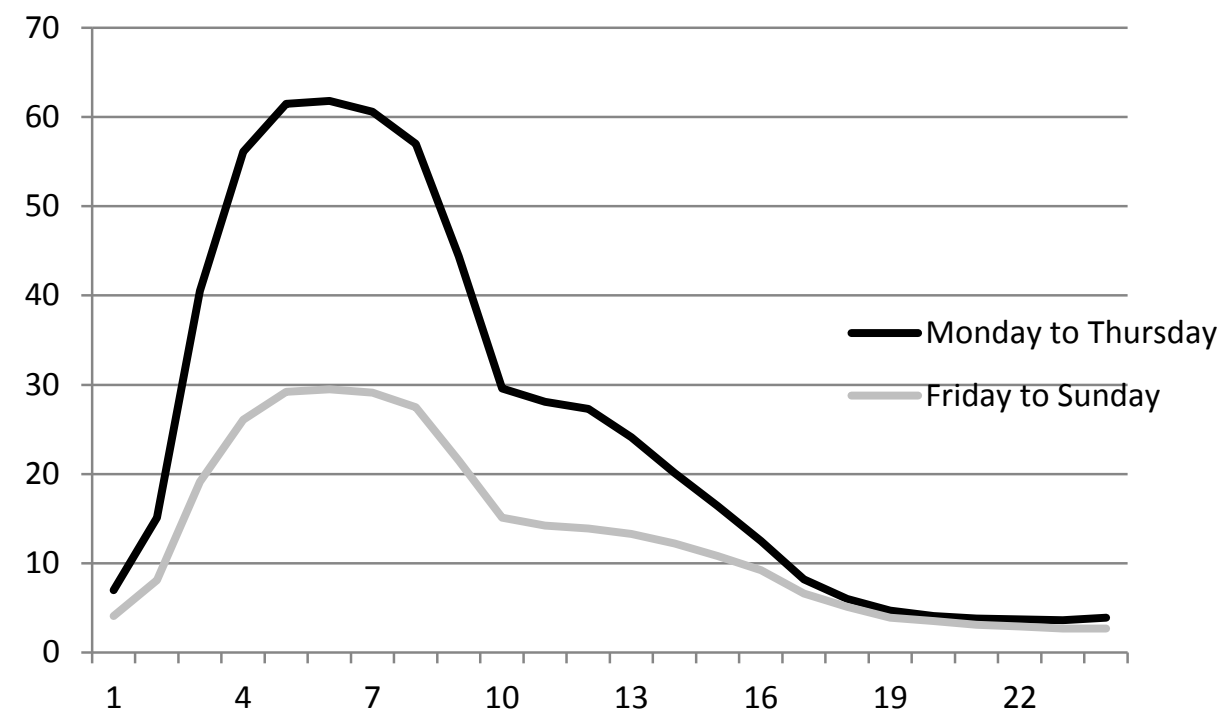

Intensive working schedule days without a break can provide useful information around modes of electricity consumption. For instance, one of the most important distinctions lays between continuous working hours -as presented in Figure 5- and split shifts, which are illustrated in Figure 6. The greatest continuity in split shifts takes place during night time between 4:00 and 7:00. A second peak in terms of simultaneous work occurs before lunch break, at 12:00. There is a very low level of simultaneous split shifts at 9:00 - a time when residential occupancy and peak demand are high. The low peak in split shifts is not backed by any equivalent drop in continuous working days. Also, continuous working days pick up again in Figure 6 unlike in Figure 5. The most direct interpretation of this phenomenon is that most of the split shift jobs are organised around meal periods, with split shifts (part-timers, night shift workers, etc.). 


\section{Figure 6-Percentage of persons working on split shifts}

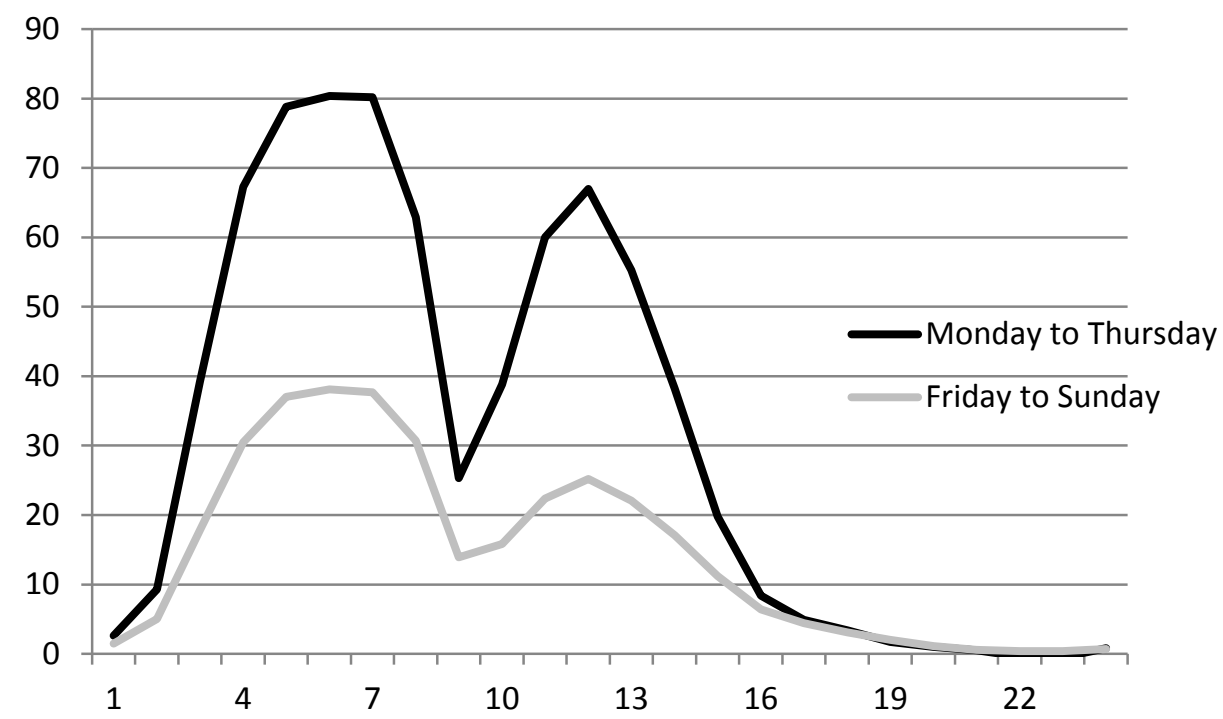

\section{Comparison with other Time Use Surveys}

\section{Comparison with the 1996 Spanish Time Use Survey}

Figure 7 compares the percentage of household with at least one occupant not sleeping in the two last Time Use Surveys in Spain. The focus of the comparison is on active occupancy, which comprises all the activities taking place in the households when people are not asleep. The trend of non-sleeping active occupants in Spain has not changed significantly between the two Time Use Surveys. Because the 1996 data consist of one-hour intervals (and not 10 minute intervals as in the 2010 data), the comparison is made on one-hour data points. The figure highlights the three peaks in active occupancy occurring in 2010, respectively $58 \%$ between $9: 30$ and 10:30, 73\% between $14: 10$ and $15: 10$ and $82 \%$ between $21: 30$ and 22:30. The 1996 active occupancy trends are smoother and seem to indicate a lower variation in occupancy than the 2010 data. Compared with 1996, the 2010 active occupancy trends are more spikey around the first part of the afternoon. Other meal-related peaks were more substantial in 1996 than in 2010. In particular, the time around 14:00 and 16:00 is associated with a lower amount of people being active in the household after lunch. The causes for this could be numerous (e.g. the increase of individuals working hours similarly related to those of other Western world countries; the decrease of the practice of siesta; and the proliferation of new practices of dining out or in the work place, which replace the habit of returning home 
for lunch). However, rather than on the causes, this paper focuses on the consequences, i.e. the impacts of lower presence in the household at that time of the day have on electricity consumption. The time spent when returning home (from work, school, etc.) in the 1996 Time Use Survey was associated principally with: (i) cooking and personal care; (ii) TV; and (iii) studying. Between the 1996 and 2010 data two phenomena took place. First, some of the cooking and TV activities of 1996 which did not take place in 2006 correspond to a net energy saving. Second, some of the studying activities were shifted to other periods of the day, with possible impacts on lighting loads.

With regards to the lower level of occupancy in 2010 at peak occupancy time (i.e. around 23:00), this can be explained with changing working patterns, number of occupants engaged in longer hours in school, and longer journeys.

Figure 7-Percentage of households with at least one occupant in the household and not sleeping

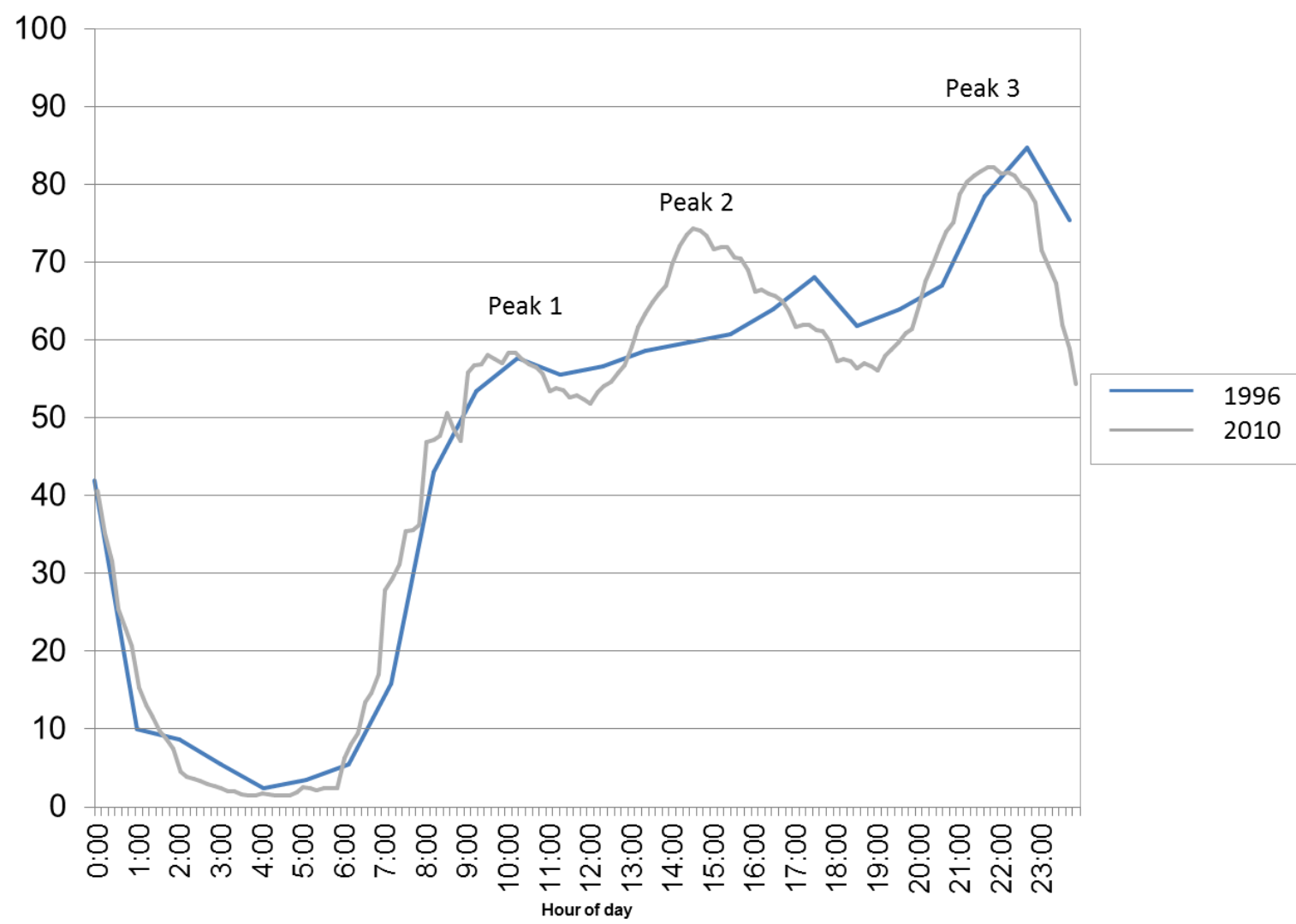


Figure 8 shows the percentage of households with at least one occupant engaged in nonsleeping activities across 15 European countries. The data for the other 14 countries besides Spain were taken from the Harmonised European Time Use Survey, a collection of national time use surveys. Compared with the 15 countries average, Spanish consumers on average spend less time in the household. Their activities in the household also take place later in the day than in other countries. This happens despite the fact that Figure 8 shows all data at Central European Time. In other words, in Figure 8 the timing of Bulgaria, Estonia, Lithuania, Latvia and UK were adjusted to Central European Time. National Time Use Survey data at 12:00 (Greenwich Meridian Time) in the UK is shifted to 13:00.

The evening peak occurs 20 minutes later than in other European countries. Consequently, peak electricity loads are also taking place later in the evening in correspondence with higher occupancy. This paper does not address these issues. Other research aiming to understand the actual impact of different occupancy levels on electricity loads would require a break-down of specific highly used appliances as well frequent activities. 
Figure 8-Households with at least one occupant in the household and not sleeping

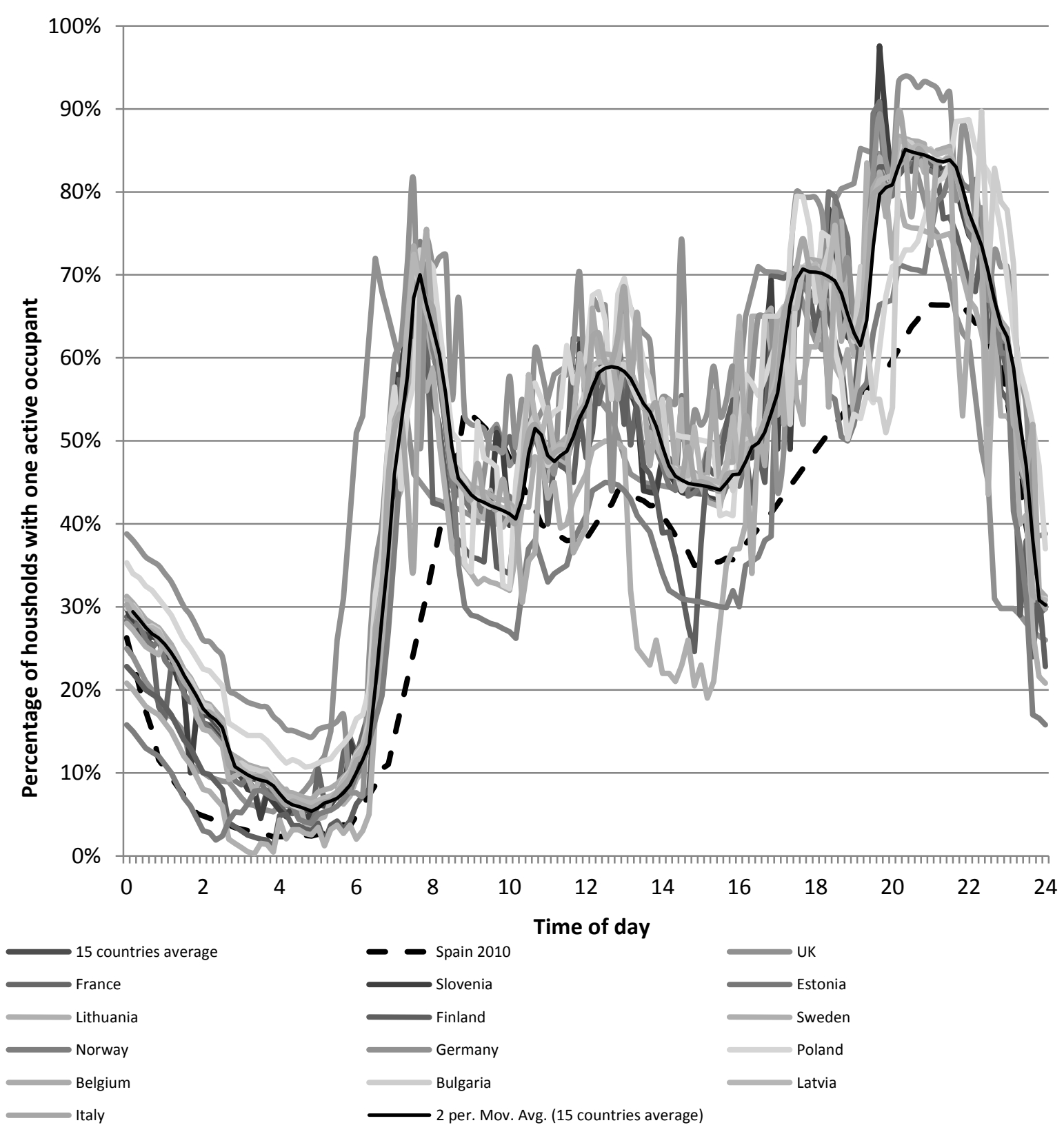

\section{Conclusions}

Interpretation of results

The analysis of the 2010 Time Use Survey highlighted areas of simultaneous practices by Spanish consumers. With a high degree of inference, simultaneous practices may provide an indication about residential electricity peak demand. Media activities are associated the highest levels of continuity and simultaneity, particularly in the early and late parts of the 
evening during weekdays. The electricity demand of media devices is flat for an average period of four hours. Certainty about the timing of peak demand for media activities can be used as a basis for differentiating residential electricity tariffs. This is similar to what occurs in the internet broadband industry where pricing is used as a peak management tool and combined with the elimination of flat rate data plans in favour of usage-based pricing. High continuity in work shifts (and the electricity loads associated with it) has different implications on demand. Rigid working hours are associated with predictable patterns around the work-related loads (e.g. computers, heaters, lights in offices), but also in terms of residential occupancy. Flexibility may be placed either in shiftable loads during long continuous working hours or through the interruptions driven by split shifts at work.

The investigation into simultaneous activities is driven by the assumption that the higher the number of people performing the same practices at the same time, the greater the likelihood of rises in peak electricity demand. The break-down of activities provided by the Spanish Time Use Survey offered the opportunity to model some of the average loads associated with household practices. The weekend peak associated with TV watching activities occurs in the evening and is in the order of about $275 \mathrm{MWh}$. The computer-related electricity loads (combining desktops and laptops) take place earlier in the day and never exceed the $20 \mathrm{MWh}$ peak.

How flexible are these peak events? A social practice theory which takes into account practices related to and offered by the device excludes the individual household's willingness to shift. For instance, traditionally TV watching has been seen as a low-flexibility and high simultaneity practice, due to the fact that the programs offered by emitters have very unique timings (Zundel and Stieß, 2011). For instance, certain programs are only broadcasted at specific times of the day. However, the introduction of digital channels along with the provision of pay-per view programs means that higher flexibility is likely in the future. Computer-related activities feature different time connotations. Unlike TV, they are not driven by a broadcaster's supply, but by social and work needs linked with the use of emails and social networks. Consequently, computer can be interpreted as a relatively flexible practice, which is increasingly combined with other practices (Heinzle, 2012). The loads of laptops, which are devices with higher electricity efficiency than desktops, present time use challenges which could not be addressed with this dataset as they are concerned with the timing of battery charge and use. 
The comparison with the previous Spanish Time Use Survey showed increases in flexibility both thanks to net decreases in cooking and TV watching and due to load shifts in studying activities. The time use data indicate changes around lunch periods. Lower household occupancy during this period of the day is not coupled by higher levels of occupancy during the evening peak.

The comparison of the Spanish data with other European time use surveys shows that the evening peak in household occupancy takes place later than in other countries. Spanish consumers feature levels of occupancy which are below the European average.

\section{Methodological issues}

The application of time-use data as tools in the search for simultaneity in electricity consumption has considerable potential, but also limitations. The employment of Spanish Time Use Survey data has resulted in five methodological issues. First, time-related occupancy data in this study are representative of average days, typically weekdays, where societal constraints standardise routine and practice of everyday life. However, some of the most sizeable peak events take place on non-average days due to either particular weather conditions -e.g. a very cold winter day in Northern Europe or a very hot summer day in North America, where the use of air conditioning is diffused (Chappells and Shove, 2005) or rare public events -e.g. a football final or a royal wedding. Second, time use data are not significant for individual users because the variation between single profiles is such that they become significant only for aggregate users. For this reason large datasets (like the national time use surveys) are more significant than detailed individual user ethnographic data on e.g. causal relations for particular timing of activities. The quantitative analysis of time use data could presented in this paper represents a snapshot of human activities and social practices. However any causal link on the flexibility of practices would have to be deferred to qualitative methods. Third, time use surveys are conducted very seldom. The Spanish surveys analysed in the paper were carried out 14 years apart. The last UK time use survey was carried out in the year 2000. Whilst most occupancy and mobility patterns may not have changed dramatically, the evolution in the use of electronic devices calls for a careful consideration of 'old' occupancy data in relation to 'new' timing of electricity demand. For instance, the old categories of TV might need to be integrated with tablets, portable media and other new ICT technologies. Fourth, the comparison of occupancy profiles among national datasets emphasises high similarities. These could be explained through 
globalisation or other reasons. Whatever the reasons might be, the high level of similarity in occupancy patterns demonstrates that, at least in developed countries, the timing of consumption is less variable than other factors that influence energy consumption (e.g. weather, appliance design, etc.). This partly explains what energy economists define as the rigidity of the residential demand curve against time and price. Fifth, time use data can only be regarded as proxies for time-related energy demand curves. This is partly because some human activities in national time use surveys cannot be associated with appliance consumption and partly due to the fact that some energy services (e.g. heating, boilers) can run in the absence of occupants.

\section{Theoretical relevance}

The attempt to link time to consumption has wider theoretical consequences for practice theory. Practice theory sees the types of activities in the household (showering, cooking, watching TV etc) as practices. People in the household engage in several practices at the same time, each with their own required paraphernalia and electricity consumption. Processes like habituation and routine imply that performance in a familiar practice is often neither fully conscious nor reflective. The concept of habitus by Bourdieu emphasises the orderliness and predictability of people's actions when faced with apparent free choices. Such habiti are spelled out and analysed in this paper. Other research using qualitative methods has highlighted the incompatibility of personal schedules within social networks. For instance, Southerton (2003) finds that partners finishing work at unpredictable times, friends and family visiting at unexpected times and work colleagues finishing at particular times despite

having flexible working hours all generate difficulties to people's scheduling of practices. Flexibility cannot be seen simply as 'interruptions' to practices, but also as the consequence of successful imposition of personal routines by others.

Electricity is not a consumable good in itself, but serves the purpose of realising activities and practices which define the social and personal space within which individuals live (Shove, 2003). We have seen how time use data enable the exploration of consumer practices in terms of simultaneity of electricity consumption patterns. However, the data analysed in this paper do not fully address issues of sustainable consumer practice because they are not combined with information on energy efficiency, which inevitably will have impacts on consumers' flexibility. A comprehensive inquiry into flexibility of demand would have to engage with the 
energy efficiency discourse. It would also address questions about physical quantity (e.g. watts and kWh of individual appliances) and not just timing of consumption (e.g. from time use data). Time use data are conceptually associated with time-use preferences. Therefore, all consumer actions carry the same weight in terms of preferences and do not explain why certain activities or practices are conducted at certain times of the day (Körmendi, 1990). Ultimately, time use data still represent crucial information with regards to the timing of electricity consumption because a significant degree of electricity demand is not associated with those activities which practice theory defines as comfort-related. It has been argued elsewhere that much of the present consumption in the wealthy industrial societies serves culturally specific needs which are distantly related to subsistence needs like food (Jalas, 2002). For example, the Spanish Time Use data show very high use of TV appliances as well as computers, which are associated with practices placed at the crossroads between work needs and leisure time.

\section{Policy implications}

High levels of simultaneity can lead to higher predictability of load profiles. For policy purposes, the predictability of practices has positive implications on the extent to which it is possible to understand the activities which trigger electricity use in the household. Moves toward this direction are demonstrated, for instance, by a recent UK Government study exploring the breakdown of activities in the home through a survey of domestic electrical product usage (DECC, 2012). The predictability of loads in principle diminishes uncertainty about mismatches between demand and supply and favours planning for flexibility. Other forms of less predictable peaks in electricity demand, for instance from sudden spikes during TV breaks are not within the scope of this paper. Spikes are generally dealt with by the Transmission System Operator with the aid of pumped storage power stations. Instead, the focused on peak demand of longer duration (a couple of hours in the morning, four to six hours in the evening) which often recur over time. The question of whether it is possible to introduce measures which could enhance flexibility of electricity demand is more complicated. On the one hand, several Governments in developed countries have been deploying In-Home Displays and other forms of feedback as ways to inform consumers about their electricity consumption with a view to decrease aggregated demand and address issues of simultaneous consumption (Darby, 2008). On the other hand, the limited success of these 
trials on -the large scale conservation effect of In-Home Displays has been assessed in the range of 3-5\% of overall household electricity consumption (McKerracher and Torriti, 2012)seems to confirm the diffidence of the practice theory literature on feedback and reflection about domestic activities. In other words, the flexibilisation requires a weakening of sociotemporal structures. The absence of simultaneity driven by social norms like eating together has been seen as by others as a synonym of flexibilisation of practice (Warde et al, 1999).One reason why to date residential demand response has not been successfully implemented in Europe is the lack of information regarding consumer practices (Torriti, 2012a). This paper attempted to fill some of these gaps. In practice, any policy intervention aimed at shifting peak electricity loads requires detailed knowledge of when consumer practices take place and how flexible they are in terms of timing and duration. The duration, continuity and interruptability of loads in the Spanish Time Use Survey indicate areas where policy-makers might prioritise automated demand response (e.g. for continuous shifts at work, especially at night) over tariff-based forms of demand side response (e.g. time of use tariffs and critical peak pricing to discourage TV during peak periods). Automated demand response does not ensure high levels of flexibility in demand loads (Hung et al, 2012), but when combined with renewable sources of energy might bring about improvements in costs which are not necessarily experiences under time of use tariffs (Torriti, 2012b).

For consumer policy and energy policy purposes, the analytical approach based on time use data has limitations, since the outcome, i.e. at what time of the day Spanish consumers carry out electricity-consuming activities either in the household or at work, is not connected with causality, i.e. the reasons why different consumers follow a given patterns of electricity demand. The limits are directly connected with the extent to which current time use data can represent a baseline on which policy-makers and utility companies might ground their interventions, for instance in the form of demand response or demand side response policies and programmes with a view to shift the timing of peak electricity loads.

\section{Acknowledgements}

This work was supported by the Engineering and Physical Sciences Research Council [grant number EP/K011723/1] as part of the RCUK Energy Programme and by EDF as part of the R\&D ECLEER Programme. 


\section{References}

Barton, J., Huang, S., Infield, D., Leach, M., Ogunkunle, D., Torriti, J. \& Thomson, M. (2013). The evolution of electricity demand and the role for demand side participation, in buildings and transport. Energy Policy, 52, 85-102.

Becker, G. (1965). Theory of the Allocation of Time, Economic Journal. September, 493-517.

Bernard, J. T., Bolduc, D., \& Yameogo, N. D. (2011). A pseudo-panel data model of household electricity demand. Resource and Energy Economics 33, 315-325.

Borenstein, S. (2005). The long-run efficiency of real-time electricity pricing. Energy Journal, 26, 93-116.

Chappells, H., \& Shove, E. (2005). Debating the future of comfort: environmental sustainability, energy consumption and the indoor environment. Building Research and Information 33, 32-40.

Cogoy, M., (1999). The consumer as a social and environmental actor. Ecological Economics 28, 385-398.

Dana J. D. (1999). Using yield management to shift demand when the peak time is unknown. The Rand Journal of Economics, 456-474.

Darby, S. (2008) Energy feedback in buildings - improving the infrastructure for demand reduction. Building Research and Information, 36(5), 499-508.

DECC (2012). Household Electricity Survey - A study of domestic electrical product usage. London: Department of Energy \& Climate Change.

EPRI (2008). Price Elasticity of Demand for Electricity: A Primer and Synthesis, Electric Electricity Research Institute, January. Retrieved from /http://my.epri. com/portal/server.pt?Abstract_id=000000000001016264S.

European Commission (2011). Energy Roadmap 2050, COM(2011) 885/2, accessed at http://ec.europa.eu/energy/energy2020/roadmap/doc/com_2011_8852_en.pdf

Faruqui, A., Sergici, S. (2009). Hosehold Response to Dynamic Pricing of Electricity-A Survey of Experimental Evidence. The Brattle Group. Retrieved from /http://www.science.smith.edu/jcardell/Readings/uGrid/House\%20DemandResp\%20Experien ce.pdfS.

Foxon, T.J. (2013). Transition pathways for a UK low carbon electricity future. Energy Policy, 52, 10-24,

Filippini, M. (1995). Swiss residential demand for electricity by time-of-use. Resource and Energy Economics, 17, 281-290. 
Gago, E. J., García, J. O., \& Estrella, A. E. (2011). Development of an energy model for the residential sector: Electricity consumption in Andalusia, Spain. Energy and Buildings, 43(6), 1315-1321.

Gershuny, J. (2000). Changing Times: Work and Leisure in Postindustrial Society. Oxford: Oxford University Press.

Giddens, A. (1984). The Constitution of Society. Cambridge: Polity.

Grunewald, P. and Torriti, J. (2013). Demand response from the non-domestic sector: early UK experiences and future opportunities. Energy Policy, 61. pp. 423-429.

Heinzle, S. L. (2012). Disclosure of Energy Operating Cost Information: A Silver Bullet for Overcoming the Energy-Efficiency Gap?. Journal of Consumer Policy, 1-22.

Hoch, S. J., \& Loewenstein, G. F. (1991). Time-inconsistent preferences and consumer selfcontrol. Journal of Consumer Research, 492-507.

Hochschild, A. R. (1997) The Time Bind: When Home becomes Work and Work becomes Home. CA: Henry Holt.

Hong, J., Johnstone, C., Torriti, J. \& Leach, M. (2012). Discrete demand side control performance under dynamic building simulation: a heat pump application. Renewable Energy, 39 (1). pp. 85-95.

IEA (2011), World Energy Outlook 2011.

Jalas, M. (2002). A time use perspective on the materials intensity of consumption. Ecological Economics, 41(1), 109-123.

Juster, F. T., Ono, H., \& Stafford, F. P. (2003). An assessment of alternative measures of time use. Sociological Methodology, 33(1), 19-54.

Kamerschen, D. R., \& Porter, D. V. (2004). The demand for residential, industrial, and total electricity, 1973-1998. Energy Economics 26, 87-100.

Kasulis, J. J., Huettner, D. A., \& Dikeman, N. J. (1981). The feasibility of changing electricity consumption patterns. Journal of Consumer Research 83, 279-90.

Körmendi, E. (1990). Preferences and time use. Time and Consumption, 143-161.

Kwan, M. P. (2002). Time, information technologies, and the geographies of everyday life, Urban Geography, 23, 471-482.

López-Rodríguez, M. A., Santiago, I., Trillo-Montero, D., Torriti, J. and Moreno-Munoz, A. (2013). Analysis and modeling of active occupancy of the residential sector in Spain: An indicator of residential electricity consumption. Energy Policy, 62, 742-751.

Mansouri, I., Newborough, M., \& Probert, D. (1996). Energy consumption in UK households: Impact of domestic electrical appliances. Applied Energy, 54(3), 211-285. 
Mattioli, G., Shove, E. and Torriti, J., (2014). The timing and societal synchronisation of energy demand. Working Paper. DEMAND Working Paper.

McLoughlin, F., Duffy, A., \& Conlon, M. (2011). Characterising domestic electricity consumption patterns by dwelling and occupant socio-economic variables: An Irish case study. Energy and Buildings, 48, 240-248.

National Statistics Institute of Spain (2010). Survey on Equipment and Use of Information Technologies and Communication in households. Available from: http://www.ine.es/jaxi/tabla.do?path=/t25/p450/a2010/10/\&file=07001. px\&type $=$ pcaxis $\& \mathrm{~L}=0$.

National Statistics Institute of Spain (2008). Household and Environment Survey. Available from: http://www.ine.es/jaxi/menu.do?type=pcaxis\&path=/t25/p500/2008/p0 $1 / \&$ file $=$ pcaxis $\#$.

Neutens, T., Schwanen, T., \& Witlox, F. (2011). The prism of everyday life: towards a new research agenda for time geography. Transport Reviews, 31(1), 25-47.

O’Connell, S. (1998). The Car in British Society: Class, Gender and Motoring 1896-1939. Manchester: Manchester University Press.

Reckwitz, A. (2002). Toward a Theory of Social Practices: A Development in Culturalist Theorizing. European Journal of Social Theory 5(2): 243-63.

Reisch, L.A. (2001). Time and Wealth. The role of time and temporalities for sustainable patterns of consumption. Time \& Society 10 (2/3), 367-385.

Reinhart, C. F. (2004). Lightswitch-2002: a model for manual and automated control of electric lighting and blinds. Solar Energy, 77(1), 15-28.

Richardson, I., Thomson, M., \& Infield, D. (2008). A high-resolution domestic building occupancy model for energy demand simulations. Energy and Buildings, 40(8), 1560-1566.

Richardson, I., Thomson, M., Infield, D., \& Clifford, C. (2010). Domestic electricity use: A high-resolution energy demand model. Energy and Buildings, 42(10), 1878-1887.

Robins, T. (1995). TV Times Time, Space and Television Scheduling. Time \& Society, 4, 397407.

Schulz, F., \& Grunow, D. (2012). Comparing diary and survey estimates on time use. European Sociological Review, 28(5), 622-632.

Shove, E. (2003). Converging conventions of comfort, cleanliness and convenience. Journal of Consumer Policy, 26(4), 395-418.

Shove, E. (2004). Efficiency and Consumption: Technology and Practice. Energy \& Environment, 15(6), 1053-1065. 
Silk, J. I., \& Joutz, F. L. (1997). Short and long-run elasticities in US residential electricity demand: a co-integration approach. Energy Economics, 19(4), 493-513.

Silverstone, R. (1993). Time, Information and Communication Technologies and the Household, Time \& Society, 2(3), 283-311.

Smart-A (2009). Smart domestic appliances supporting the system integration of renewable energy, Public final report accessed at /http://www.smart-a.org/index.phpS.

Southerton, D. (2003). 'Squeezing Time': Allocating Practices, Coordinating Networks and Scheduling Society. Time \& Society, 12(1), 5-25.

Thorsnes, P., Williams, J., \& Lawson, R. (2012). Consumer responses to time varying prices for electricity. Energy Policy, 49, 552-561.

Torriti, J. (2012a). Demand side management for the European Supergrid: occupancy variances of European single-person households. Energy Policy, 44. pp. 199-206.

Torriti, J. (2012b). Price-based Demand Side Management: assessing the impacts of Time-ofUse tariffs on residential electricity demand and peak shifting in Northern Italy. Energy 44 (1). pp. 576-583.Torriti, J. (2014). A review of time use models of residential electricity demand. Renewable and Sustainable Energy Reviews, 37. pp. 265-272

Torriti, J., Hassan, M. and M. Leach (2010). Demand Response experience in Europe: policies, programs and implementation. Energy, 35(4), pp. 1575-1583.

Torriti, J. and Grünewald, P. (2014). Demand side response: patterns in Europe and future policy perspectives under capacity mechanisms. Economics of Energy \& Environmental Policy, 3 (1). pp. 87-105.

Varman, M., Mahlia, T.M.I., \& Masjuki, H.H. (2006). Method for calculating annual energy efficiency improvement of TV sets. Energy Policy, 34, 2429-2432.

Vikat, A., \& Boko, D (2013). Guidelines for Harmonising Time Use Surveys. United Nations Economic Commission for Europe-Task Force on Time Use Surveys. Available at http://www.unece.org/fileadmin/DAM/stats/documents/ece/ces/2013/TimeUseSurvey_Guidel ines_for_consultation.pdf

Walker, G. (2014). The dynamics of energy demand: change, rhythm and synchronicity. Energy Research \& Social Science, 1, 49-55.

Widén, J., Lundh, M., Vassileva, I., Dahlquist, E., Ellegård, K., \& Wäckelgård, E. (2009a). Constructing load profiles for household electricity and hot water from time-use dataModelling approach and validation. Energy and Buildings, 41(7), 753-768.

Widén, J., Nilsson, A. M., \& Wäckelgård, E. (2009b). A combined Markov-chain and bottomup approach to modelling of domestic lighting demand. Energy and Buildings, 41(10), 10011012. 
Widén, J., \& Wäckelgård, E. (2010). A high-resolution stochastic model of domestic activity patterns and electricity demand. Applied Energy, 87(6), 1880-1892.

Wilke, U., Haldi, F., Scartezzini, J. L., \& Robinson, D. (2012). A bottom-up stochastic model to predict building occupants' time-dependent activities. Building and Environment 60, 254264.

Yao, R. \& Steemers, K. (2005). A method of formulating energy load profile for domestic buildings in the UK. Energy and Buildings 37, 663-671.

Yun, G. Y., Tuohy, P., \& Steemers, K. (2009). Thermal performance of a naturally ventilated building using a combined algorithm of probabilistic occupant behaviour and deterministic heat and mass balance models. Energy and buildings, 41(5), 489-499.

Zundel, S., \& Stieß, I. (2011). Beyond Profitability of Energy-Saving Measures-Attitudes Towards Energy Saving. Journal of Consumer Policy, 34(1), 91-105. 